\title{
Erratum to: Trace metal concentrations in tissues of two tinamou species in mining areas of Bolivia and their potential as environmental sentinels
}

\author{
Álvaro Garitano-Zavala • Javier Cotín • \\ Miquel Borràs · Jacint Nadal
}

Published online: 10 October 2009

(C) Springer Science + Business Media B.V. 2009

\section{Erratum to: Environ Monit Assess DOI 10.1007/s10661-009-1139-7}

The original version of this article unfortunately contained a mistake. Table 3 was incorrect. The correct table is given below.

The online version of the original article can be found at http://dx.doi.org/10.1007/s10661-009-1139-7.

Á. Garitano-Zavala ( $\triangleleft)$

Unidad de Manejo y Conservación de Fauna, Instituto de Ecología, Universidad Mayor de San Andrés,

Casilla 10077, La Paz, Bolivia

e-mail: agaritanozavala@umsa.bo

J. Cotín · J. Nadal

Secció de Vertebrats, Departament de Biologia

Animal, Facultat de Biologia, Universitat de

Barcelona, Av. Diagonal 645, 08028

Barcelona, Spain

M. Borràs

Unitat de Toxicologia Experimental i Ecotoxicologia,

Centre de Recerca en Toxicologia, Plataforma

Tecnològica del Parc Científic de Barcelona,

Barcelona, Spain
Table 3 Non-parametric correlations between trace metal concentrations in each tissue type of the Ornate Tinamou (Nothoprocta ornata)

\begin{tabular}{lllll}
\hline & Tissues & As & $\mathrm{Cd}$ & $\mathrm{Pb}$ \\
\hline $\mathrm{Cd}$ & Liver & $0.71(<0.001)$ & & \\
& Kidney & $0.51(0.001)$ & & \\
& Feather & $0.68(<0.001)$ & & \\
$\mathrm{Pb}$ & Liver & $0.71(<0.001)$ & $0.67(<0.001)$ & \\
& Kidney & $0.62(<0.001)$ & $0.55(<0.001)$ & \\
& Feather & $0.53(0.001)$ & $0.56(<0.001)$ & \\
$\mathrm{Sb}$ & Liver & $0.75(<0.001)$ & $0.71(<0.001)$ & $0.84(<0.001)$ \\
& Kidney & $0.65(<0.001)$ & $0.50(0.001)$ & $0.76(<0.001)$ \\
& Feather & $0.79(<0.001)$ & $0.70(<0.001)$ & $0.85(<0.001)$ \\
\hline
\end{tabular}

The Spearman's Rho value is given in each box and the $p$ value in brackets. $N=37$ for feather and $N=41$ for liver and kidney 